\title{
Normal extinction and reinstatement of morphine-induced conditioned place preference in the GluA1-KO mouse line
}

\section{Kiiskinen, Tuomo}

2019-08

Kiiskinen , T , Korpi , E R \& Aitta-aho , T 2019 , ' Normal extinction and reinstatement of morphine-induced conditioned place preference in the GluA1-KO mouse line ', Behavioural Pharmacology, vol. 30 , no. 5 , pp. 405-411 . https://doi.org/10.1097/FBP.0000000000000449

http://hdl.handle.net/10138/323398

https://doi.org/10.1097/FBP.0000000000000449

cc_by_nc

acceptedVersion

Downloaded from Helda, University of Helsinki institutional repository.

This is an electronic reprint of the original article.

This reprint may differ from the original in pagination and typographic detail.

Please cite the original version. 
Normal Extinction and Reinstatement of Morphine-Induced Conditioned Place Preference in GluA1-KO Mouse Line

Running title: GluA1 in morphine extinction and reinstatement

Tuomo Kiiskinen ${ }^{1}$, Esa R. Korpi ${ }^{1}$ and Teemu Aitta-aho ${ }^{1}$

${ }^{1}$ Department of Pharmacology, Faculty of Medicine, University of Helsinki, Finland

correspondence:

Teemu Aitta-aho, PhD

Department of Pharmacology, Faculty of Medicine

P.O.Box 63, FI-00014, University of Helsinki, Finland

Email: teemu.aitta-aho@helsinki.fi

\section{Funding}

This work was supported by Finnish Foundation for Alcohol Studies (TA), the Academy of Finland (ERK) and the Sigrid Juselius foundation (ERK).

Conflicts of interest: none declared. 


\section{Abstract}

Extinction and reinstatement of morphine-induced conditioned place preference were studied in glutamate AMPA-receptor GluA1 subunit-deficient mice (global GluA1 KO mice). In line with previous findings, both acquisition and expression of conditioned place preference to morphine (20 mg/kg. s.c.) were fully functional in GluA1 KO mice as compared to wildtype littermate controls (GluA1 WT), therefore, enabling the study of extinction. With a 10-session extinction paradigm, the GluA1 KO mice exhibited complete extinction similar to that of the GluA1 WT mice. Morphine-induced reinstatement (10 mg/kg s.c.) was detected in both mouse lines. GluA1 $\mathrm{KO}$ mice moved more during all the phases of the experiment, including the place conditioning trials, extinction sessions, and place preference tests. The results suggest that GluA1 subunit may be dispensable or prone to compensation at the neural circuitries delineating extinction and reinstatement. The GluA1 KO mice display altered long-term between-session habituation, which extends longer than previously anticipated.

Keywords: morphine, glutamate, AMPA receptor, conditioned place preference, extinction, reinstatement 


\section{Introduction}

Abused drugs promote adaptive neuroplastic changes in the brain, which are thought to account for their addictive properties such as withdrawal and relapse after extinction (Volkow and Morales, 2015). The reinstatement of drug use after a period of abstinence (relapse) is one of the core symptoms of addictive disorders, but its mechanisms remain incompletely understood. The drug-induced changes can resemble learning-like mechanisms, possibly bridging the initial drug responses over the abstinence period to finally become recruited when the drug is available again (Kelley, 2004).

These kinds of long term adaptations may be mediated by the glutamatergic receptor system, which has been shown to be important in both learning and drug addiction (Kauer and Malenka, 2007). As the amino acid glutamate is the main excitatory neurotransmitter in the brain, especially the AMPA-type glutamate receptors readily undergo adaptive changes such as altered subunit composition of membrane-targeted receptors that promote an increase in synaptic strength (Korpi et al., 2015).

GluA1 subunit of the AMPA receptors is one candidate substrate in mediating neuroplasticity (Henley and Wilkinson, 2016). Functionally, the expression levels of GluA1 subunit can change in response to learning or administration of abused drugs, and this has been shown to relate to an increase in synaptic strength (Kopec et al., 2007; Kourrich et al. 2015; Lee et al., 2003; Ungless et al., 2001). The GluA1 subunit-containing receptors are trafficked in postsynaptic membrane during long-term potentiation, a process in which phosphorylation of GluA1 subunit facilitates the adaptive changes (Hayashi et al., 2000; Lee et al., 2003; Terashima et al. 2017).

Drug addiction-related neuroadaptation in reward processing is localized e.g. to the ventral tegmental area, in which morphine and cocaine exposure increases GluA1 subunit expression in dopamine (DA) neurons (Fitzgerald et al., 1996). Viral vector-mediated overexpression of GluA1 subunit in the VTA increases drug-induced locomotor sensitization and conditioned place preference (CPP), suggesting that the upregulation of GluA1 subunit may mediate the drug-induced synaptic strengthening in VTA DA neurons (Carlezon et al., 1997). In the central amygdala, a brain region important for establishment of conditioned effects, downregulation of GluA1 subunit decreases morphine-induced CPP (Cai et al., 2013).

However, to extinquish and to reinstate associative learning provoked by a drug reward, brain areas other than VTA may play significant roles. This is of importance as synaptic strength enhancing neuroplastic processes of the VTA DA neurons are transient with a time period of few days (Argilli et al., 2008; Heikkinen et al., 2009), and thus cannot explain the mechanisms of relapses in drug use. As the expression spectrum of GluA1 subunit covers many addiction-relevant areas such as the striatum, hippocampus, cerebral cortex and amygdala (Keinanen et al., 1990; Petralia and Wenthold, 1992), the study of the role of GluA1 is warranted in behaving animals. Therefore, we chose to use a mouse line globally lacking the GluA1 subunit (Zamanillo et al., 1999) to study morphine's neuroadaptive responses. Specifically, the mice were tested for morphine-induced 
locomotor sensitization, conditioned place preference (CPP), its extinction and morphineinduced reinstatement. 


\section{Materials and Methods}

\section{Ethics}

All experimental procedures were carried out with the approved permissions (ESAVI0010026/041003/2010 and ESAVI-2010-05600/Ym-23) and had ethical approval from the State Provincial Government of Southern Finland. All efforts were made to minimise the number and suffering of animals.

Animals

The gene gria1 encoding for glutamate AMPA-type receptor subunit GluA1 was inactivated to generate gria1-/- mouse line (KO) (Zamanillo et al., 1999). KO mouse line was backcrossed to C57BL/6J mouse line (Harlan BV., Horst, The Netherlands) at least for 10 times prior to breeding of the animals for the experiments by heterozygous breeding. The $\mathrm{KO}$ and the gria1+/+ wildtype littermate controls (WT) were produced, and both sexes were used. They were genotyped using PCR from ear-tip biopsy samples as described (Zamanillo et al., 1999). The experimental animals were housed 2-6 animals to a cage from weaning until used at the age of 2.5 to 4 months. All animals were naïve to pharmacological and handling manipulations until the start of the experiments. The animal facility had lights on from 6 a.m. until 6 p.m., temperature set at $20 \pm 1^{\circ} \mathrm{C}$ and relative humidity at $50 \pm 1 \%$. Water and standard rodent food pellets (Harlan) were available $a d$ libitum. All experiments were performed during the light phase between 8 a.m. and 3 p.m., when the animals exhibited similar spontaneous locomotor activities (Procaccini et al. 2011).

\section{Morphine injections}

Morphine hydrochloride (Yliopiston apteekki, Helsinki, Finland) was daily dissolved in $0.9 \%$ $\mathrm{NaCl}$ solution (saline) and injected subcutaneously in a volume of $10 \mathrm{ml} / \mathrm{kg}$, unless otherwise stated. Control animals were injected with equal volume of saline.

\section{Conditioned place preference (CPP) paradigm}

Conditioning and place preference testing was performed in eight polycarbonate cages $(45 \times 22.5 \times 15 \mathrm{~cm}$; Tecniplast, Buguggiate, Italy) covered with transparent lids with ventilation holes. The cage floors were covered with either one of the two floor materials, which acted as conditioning stimuli: plastic floor consisting of 1.2-cm-wide flat bars separated by $0.5 \mathrm{~cm}$ from each other and metal floor of stainless steel wire mesh with 1 $\mathrm{mm}$ holes. These materials were selected from several different materials in 15-min preconditioning preference tests using a separate batch of naïve KO and WT mice, with the above-described floor materials inducing no preference for either of them in neither mouse line (data not shown). Locomotor activity (distance traveled in meters) and location of each 
mouse in place preference test (time spent in the morphine-associated side) was determined by Ethovision 3.0 video tracking system (Noldus Information Technology BV., Wageningen, The Netherlands), based on video image analysis of the center-point of the mouse. Between the trials, all cages and floors were thoroughly washed with water and dried to remove the odors.

In the conditioning phase, one 30-min trial was performed per day for a total of eight days, separated by a two-day break after the first 4 trials. Each day, a saline injection was paired with either plastic or metal floor for one group of the animals (CS- trial, conditioning stimulus with saline) and a $20-\mathrm{mg} / \mathrm{kg}$ morphine injection was paired with the plastic or metal floor for the other group of the animals (CS+ trial, conditioning stimulus with morphine). The next day, the animals that started with a CS- trial now underwent a CS+ trial, and vice versa. This procedure was continued until the eight conditioning trials were performed thus resulting in four CS+ and four CS- trials for every animal, half of the animals receiving morphine paired with plastic and the other half with metal. Immediately after the injections, the mice were placed into the cages for $30 \mathrm{~min}$.

The first place preference test was performed $24 \mathrm{~h}$ after the last conditioning trial. The cage floor was covered with both plastic and metal materials, thereby bisecting it into two distinct equally sized zones without any vertical borders in between them. Thus, during both the place preference test trial and conditioning trials the area of the arena was identical, i.e. the animals had access to the whole apparatus during all phases of the experiment. Spatial orientation of the materials was balanced for the test groups. The animals were injected with saline and placed in the center of the cage. Locomotor activity and location of the mouse were observed for $15 \mathrm{~min}$. The results were presented as time spent in the metal floor zone, which indicated place preference if there was a significant positive difference between the times for mice paired with morphine and metal or plastic floors.

The extinction phase followed the conditioning phase, so that one 30-min trial was performed each day and the different floor materials (CS+ or CS- trial) were used every other day. However, now both CS+ and CS- floor materials were paired with saline injections without any morphine injections. The extinction phase contained first five trials on consecutive days, followed by two days of rest in the home cages, five more consecutive days of extinction, two days of rest, two more extinction trials on consecutive days and then finally the day after the second place preference test (performed identically to the one after the conditioning phase).

The reinstatement place preference test was performed one day after the extinction place preference test. The protocol remained the same except for the animals receiving a subcutaneous injection with $10 \mathrm{mg} / \mathrm{kg}$ morphine.

Statistics 
Data were analyzed with either two- or three-way ANOVA with repeated measures when applicable, followed by either post hoc Bonferroni test (more than two groups) or by independent samples unpaired t-test (two groups). Statistical analyses were performed by using the statistical software packages SPSS 20.0 for Windows (SPSS, Chicago, IL, USA) and the Prism 6.0 program (GraphPad Software). Statistical significance was set at $p<0.05$. Data are expressed as means \pm standard errors of the mean (SEM). No significant sex effects or interactions were found in any of the statistical analyses, and thus the sexes were pooled for data shown in the figures.

\section{Results}

\section{Locomotor activity during the conditioning trials}

Locomotor activity during the conditioning trials is depicted in Fig. $1 \mathrm{~A}$. Morphine produced an increase in locomotor activity in both WT and KO mice (drug effect, F1,80 =128.88, p < 0.001 ), and this effect increased over the conditioning trials in both genotypes suggesting that morphine-induced sensitization occurred (drug $\times$ trial interaction, F3,240 $=82.10, p<$ $0.001)$. Separate analysis for saline trials revealed that throughout the CS-conditioning trials the KO mice moved more than WT mice (genotype effect, F1,40 = 34.83, $\mathrm{p}<0.001$ ), and that their habituation was stronger than that of WT mice (genotype $\times$ trial interaction, $\mathrm{F} 3,120=2.95, \mathrm{p}<0.05$ ). Due to differing locomotor activity in the saline trials between the genotypes, difference scores between each CS+ and corresponding CS- trials were calculated (Fig. 1B). Although KO mice displayed less morphine-induced activation compared to WT mice in the beginning of the conditioning phase (genotype $\times$ trial interaction, $\mathrm{F} 3,120=3.42, \mathrm{p}<0.05$ ), their locomotor activity was at equal level with the WT mice during the last two conditioning trials (Fig. 1B; WT vs. KO, p > 0.05, t-test). This suggests that morphine-induced psychomotor sensitization developed to the same degree in WT and KO mice.

\section{Place preference test}

After the conditioning trials, the place preference test was conducted (Fig. 2). Both genotypes displayed significant place preference (Fig. 2A; conditioning subgroup effect, $\mathrm{F} 1,36=18.55, \mathrm{p}<0.001$ ) equally (genotype $\times$ conditioning subgroup interaction, $\mathrm{F} 1,36=$ $0.32, p>0.05$ ). The expression of place preference was evident throughout the 15-min place preference test trial as evidenced by a non-significant timebin $\times$ conditioning subgroup interaction (F2,72 $=0.06, p>0.05)$ in an analysis of 5 -min time-bins, also equally in both genotypes (timebin $\times$ conditioning subgroup $\times$ genotype interaction, F2,72 $=1.10, p>0.05)$. During the place preference test trial, the KO mice moved more than WT mice (Fig. 2B; genotype effect, F1,40 = 37.69, $\mathrm{p}<0.001$ ). 


\section{Extinction}

After the place preference test, ten consecutive extinction trials were performed. During these trials the locomotor activity of the KO mice was consistently above that of WT mice (Fig. 3; genotype effect, $F 1,40=22.73, p<0.001$ ). Extinction of the place preference was evidenced by the non-significant conditioning subgroup effect (Fig. 4A; F1,36 $=0.02, p>$ 0.05 ) equally in both genotypes (genotype $x$ conditioning subgroup interaction, $F 1,36=$ $1.05, p>0.05$ ). The mice showed extinquished place preference over the 15-min extinction test trial in an analysis of 5 -min timebins (timebin $\times$ conditioning subgroup interaction, $\mathrm{F} 2,72=0.31, \mathrm{p}>0.05$; timebin $\times$ conditioning subgroup $\times$ genotype interaction, $\mathrm{F} 2,72=0.73, \mathrm{p}>0.05)$. Locomotor activity during the extinction test trial was higher in the KO than WT mice (Fig. 4B; genotype effect, $F 1,40=14.00, p<0.01$ ).

\section{Drug-induced reinstatement}

After successful extinction, morphine-induced reinstatement was provoked in WT and KO mice by injecting $10 \mathrm{mg} / \mathrm{kg}$ morphine. Significant place preference was evident (Fig. 5A; conditioning subgroup effect, $F 1,36=10.19, p<0.01$ ) in both genotypes (genotype $\times$ conditioning subgroup interaction, $\mathrm{F} 1,36=0.33, \mathrm{p}>0.05)$. Reinstated place preference was evident throughout the test trial (timebin $\times$ conditioning subgroup interaction F2,72= $0.24, p>0.05$ ) equally in both genotypes (timebin $\times$ conditioning subgroup $x$ genotype interaction, $F 2,72=0.19, p>0.05$ ). During the reinstatement test trial, locomotor activity was equal between genotypes (Fig. 5B; genotype effect, F1,36 = 0.07, p > 0.05). 


\section{Discussion}

In the present study, we found that extinction from morphine-induced CPP as well as morphine-induced reinstatement were unchanged in the mouse line lacking the glutamate AMPA-type receptor subunit GluA1. As the used mouse model represents a global knockout, our study involved all brain areas relevant to extinction and reinstatement of opioid-induced CPP. Many of these areas contain high or moderate levels of GluA1 subunits. Importantly, both WT and KO mice developed an equally strong morphineinduced CPP in line with previous findings (Aitta-aho et al., 2012; Mead et al., 2005), thus enabling to study extinction and reinstatement and justifying direct comparisons.

For the extinction of drug responding, our results contrast those with GluA1 deficiency directed in brain region-specific or cell type-specific manner, or those with detection of hippocampal GluA1 phosphorylation. First, rendering all DA neurons deficient of GluA1 subunits by genetic targeting prevented extinction of cocaine-induced CPP (Engblom et al., 2008). Second, shRNA-mediated downregulation of GluA1 expression in the central amygdala slowed down extinction of morphine-induced CPP (Cai et al., 2013). These mice also developed CPP to a lesser extent as compared to the control mice, while normal CPP was found in the global KO mice (this study). Third, in the hippocampus, a brain region combining both the importance for the extinction processing as well as GluA1 subunit expression at the highest level, an increase in phosphorylation of GluA1 subunit during the extinction phase of CPP was detected (Billa et al., 2009). In our study with the global KO mice we observed normal extinction of morphine CPP despite the absence of hippocampal GluA1. In summary, comparison of these results with the current data suggests an existence of brain regions and neural circuitries in which endogenous GluA1 expression inhibits the extinction process. Previous data point toward this assumption, as an increase in GluA1 functioning has been linked to delayed extinction with the opioid antagonist naltrexone (Kibaly et al., 2016). More generally, some forms of learning are promoted despite the absence of GluA1 in the KO mice (Sanderson et al., 2009).

To successfully achieve a comprehensive extinction of morphine-induced CPP we utilised an extended extinction phase in the current experiment. Our results raise an interesting question of possible different rates of the extinction development between the WT and KO mice. With a shorter extinction phase, it could be clarified whether the initial development of extinction is GluA1-dependent.

There are no previous reports on reinstatement of drug-induced CPP in GluA1-deficient mice. Here a morphine-induced reinstatement of the CPP was evident in both WT and KO mice, showing no obligatory requirement for GluA1 subunit function in post-extinction relapse behavior. Normally occurring extinction in the KO mice facilitated the study on reinstatement of extinguished morphine CPP. Other data point toward the attenuation of cocaine seeking when GluA1 functionality in the nucleus accumbens is suppressed by limiting either its transcription (Ping et al., 2008), trafficking into the synapses (Anderson et al., 2008), action by an antagonist (White et al., 2016), or gating by inactive 'pore-dead' GluA1 subunits (White et al., 2016). Also oscillations at the neuronal circuitries may lead to 
detrimental consequences on extinguished drug use. In support to that, reinstatement of cocaine seeking can be provoked by hippocampal theta oscillations (Vorel et al., 2001), a type of bursting activity driving plasticity that has been shown to be intact in GluA1deficient mice (Hoffman et al., 2002; Romberg et al., 2009). In the neurobiology of reinstatement, in addition to the AMPA receptor-related glutamatergic factors, there may also be other factors that are of importance (Bossert et al., 2013). There is evidence for AMPA/kainate-dependent glutamatergic function in prefrontal-amygdaloid and prefrontalaccumbal circuitries (LaLumiere and Kalivas, 2008; Peters et al., 2008). Opioid-evoked reinstatement is dependent on the action of nucleus accumbens GluN2B subunitcontaining NMDA receptors (Ge et al., 2017) and in cocaine-evoked reinstatement, the importance of GluA2 (Schmidt et al., 2014; Wiggins et al., 2011) and metabotropic glutamate receptors mGluR2/3, mGluR5 and mGluR7 (Kupchik et al., 2012; Li et al., 2010; Mahler et al., 2014) have been indicated.

As known for its pivotal role in conditioned drug responses, the amygdala also contains GluA1 subunits at a relatively high level (Keinanen et al., 1990; Petralia and Wenthold, 1992). Because the GluA1-KO mouse model reproduces to some extent the appetitive learning deficits of the animals with basolateral amygdala lesions (Mead and Stephens, 2003), it is interesting to note that the basolateral amygdala lesions lead to diminished drug seeking (Yun and Fields, 2003) while the GluA1-KO mice respond normally (this study). Another brain region with GluA1 subunit-containing receptors implicated in progression of drug addiction is the habenula (Petralia and Wenthold, 1992). In the habenula, cocaine administration increases cell membrane trafficking of GluA1 subunits equally to the well-studied mesolimbic circuitries, but with the behavioural consequence of provoking depressive symptoms as screened with forced swim and tail suspension tests (Meye et al., 2015). When these results are compared either with those detecting increased VTA GluA1 levels in response to abused drugs (Fitzgerald et al. 1996) or with those in which upregulation of VTA GluA1 levels sensitize mice to morphine (Carlezon et al. 1997), it can be noted that an increase in the GluA1 levels is not always linked to addiction-promoting effects. Although no conditioned place avoidance was detected in the study of Meye et al. (2015), these data raise a possibility that there are brain circuitries in which downregulation of GluA1 may promote the development of addictive cascades such as drug conditioning, inhibition of extinction, and blockade of reinstatement.

The KO mice exhibited an absence of habituation of their exploratory activity in the nonhome-cage environment during all the phases of the current behavioral protocol including acquisition, expression, extinction, and reinstatement of the CPP. These findings extend the previously reported acute novelty-induced hyperlocomotion of the KO mice (Aitta-aho et al., 2012; Bannerman et al., 2004; Cowen et al., 2003; Maksimovic et al., 2014; Vekovischeva et al., 2004; Wiedholz et al., 2008). This contrasts the normal home cage activity of the KO mice (Procaccini et al., 2011; Wiedholz et al., 2008) suggesting a noncompensating between-session habituation deficit.

Together, the acquisition, expression, extinction and reinstatement of morphine-induced CPP are evident and of equal strength in mice deficient in the GluA1 subunit in 
comparison to the littermate WT control mice. Thus, the global deficiency does not reproduce the behavioural effects in conditioned responses as seen by other cell-type or brain-region selective methods. When absent, the role of GluA1 function can be fully compensated by other, still to be identified, processes in relation to morphine-induced behaviors. One interesting neuroplasticity-related deficit in the GluA1-KO mice is the absence of persistently increased AMPA/NMDA receptor-mediated current ratios in the VTA dopamine neurons $24 \mathrm{~h}$ after a single dose of morphine (Aitta-aho et al., 2012), which should have affected the effects of morphine in the present study. However, missing neuroplasticity was largely due to already high AMPA/NMDA ratios in drug-naïve GluA1KO mice, suggesting compensation by other AMPA receptor subunits or by reduced NMDA currents.

Here, we have studied extinction and reinstatement of morphine-induced CPP in AMPA receptor GluA1-subunit deficient mouse line. In addition to the widely studied drug reward pathways the use of this mouse line enables a global study of various drug memoryrelevant brain circuitries and brain regions harboring GluA1, such as the amygdala and hippocampus. Although GluA1-KO mice show extinguished morphine CPP followed by unmodified reinstatement, the current results provide novel GluA1-specific data on these behavioral phenomena. 


\section{References}

Aitta-aho T, Möykkynen T, Panhelainen A, Vekovischeva O, Bäckström P, Korpi ER (2012). Importance of GluA1 subunit-containing AMPA glutamate receptors for morphine statedependency. PloS One 7:e38325.

Anderson SM, Famous KR, Sadri-Vakili G, Kumaresan V, Schmidt HD, Bass CE, et al. (2008). CaMKII: a biochemical bridge linking accumbens dopamine and glutamate systems in cocaine seeking. Nat Neurosci 11:344-53.

Argilli E, Sibley DR, Malenka RC, England PM, Bonci A (2008). Mechanism and time course of cocaine-induced long-term potentiation in the ventral tegmental area. $J$ Neurosci 28:9092-100.

Bannerman DM, Deacon RMJ, Brady S, Bruce A, Sprengel R, Seeburg PH, et al. (2004). A comparison of GluR-A-deficient and wild-type mice on a test battery assessing sensorimotor, affective, and cognitive behaviors. Behav Neurosci 118:643.

Billa SK, Sinha N, Rudrabhatla SR, Morón JA (2009). Extinction of morphine-dependent conditioned behavior is associated with increased phosphorylation of the GluR1 subunit of AMPA receptors at hippocampal synapses. Eur J Neurosci 29:55-64.

Bossert JM, Marchant NJ, Calu DJ, Shaham Y (2013). The reinstatement model of drug relapse: recent neurobiological findings, emerging research topics, and translational research.

Psychopharmacology 229:453-76.

Cai YQ, Wang W, Hou YY, Zhang Z, Xie J, Pan ZZ (2013). Central amygdala GluA1 facilitates associative learning of opioid reward. $J$ Neurosci 33:1577-88.

Carlezon WA, Jr., Boundy VA, Haile CN, Lane SB, Kalb RG, Neve RL, et al. (1997). Sensitization to morphine induced by viral-mediated gene transfer. Science 277:812-4.

Cowen MS, Schroff KC, Gass P, Sprengel R, Spanagel R (2003). Neurobehavioral effects of alcohol in AMPA receptor subunit (GluR1) deficient mice. Neuropharmacology 45:325-33.

Engblom D, Bilbao A, Sanchis-Segura C, Dahan L, Perreau-Lenz S, Balland B, et al. (2008). Glutamate receptors on dopamine neurons control the persistence of cocaine seeking. Neuron 59:497-508.

Fitzgerald LW, Ortiz J, Hamedani AG, Nestler EJ (1996). Drugs of abuse and stress increase the expression of GluR1 and NMDAR1 glutamate receptor subunits in the rat ventral tegmental area: common adaptations among cross-sensitizing agents. J Neurosci 16:274-82.

Ge F, Wang N, Cui C, Li Y, Liu Y, Ma Y, et al. (2017). Glutamatergic projections from the entorhinal cortex to dorsal dentate gyrus mediate context-induced reinstatement of heroin seeking. Neuropsychopharmacology 42:1860-70

Hayashi Y, Shi SH, Esteban JA, Piccini A, Poncer JC, Malinow R (2000). Driving AMPA receptors into synapses by LTP and CaMKII: requirement for GluR1 and PDZ domain interaction. Science 
287:2262-7.

Heikkinen AE, Moykkynen TP, Korpi ER (2009). Long-lasting modulation of glutamatergic transmission in VTA dopamine neurons after a single dose of benzodiazepine agonists. Neuropsychopharmacology 34:290-8.

Henley JM, Wilkinson KA (2016). Synaptic AMPA receptor composition in development, plasticity and disease. Nat Rev Neurosci. 17:337-50.

Hoffman DA, Sprengel R, Sakmann B (2002). Molecular dissection of hippocampal theta-burst pairing potentiation. Proc Natl Acad Sci USA 99:7740-5.

Kauer JA, Malenka RC (2007). Synaptic plasticity and addiction. Nat Rev Neurosci. 8:844-58.

Keinanen K, Wisden W, Sommer B, Werner P, Herb A, Verdoorn TA, et al. (1990). A family of AMPA-selective glutamate receptors. Science 249:556-60.

Kelley AE (2004). Memory and addiction: shared neural circuitry and molecular mechanisms. Neuron 44:161-79.

Kibaly C, Kam AY, Loh HH, Law PY (2016). Naltrexone Facilitates Learning and Delays Extinction by Increasing AMPA Receptor Phosphorylation and Membrane Insertion. Biol Psychiatry 79:906-16.

Kopec CD, Real E, Kessels HW, Malinow R (2007). GluR1 links structural and functional plasticity at excitatory synapses. J Neurosci 27:13706-18.

Korpi ER, den Hollander B, Farooq U, Vashchinkina E, Rajkumar R, Nutt DJ, et al. (2015). Mechanisms of Action and Persistent Neuroplasticity by Drugs of Abuse. Pharmacol Rev 67:8721004.

Kourrich S, Calu DJ, Bonci A (2015). Intrinsic plasticity: an emerging player in addiction. Nat Rev Neurosci 16: 173-184.

Kupchik YM, Moussawi K, Tang X-C, Wang X, Kalivas BC, Kolokithas R, et al. (2012). The effect of $\mathrm{N}$-acetylcysteine in the nucleus accumbens on neurotransmission and relapse to cocaine. Biol Psychiatry 71:978-86.

LaLumiere RT, Kalivas PW (2008). Glutamate release in the nucleus accumbens core is necessary for heroin seeking. J Neurosci 28:3170-7.

Lee HK, Takamiya K, Han JS, Man H, Kim CH, Rumbaugh G, et al. (2003). Phosphorylation of the AMPA receptor GluR1 subunit is required for synaptic plasticity and retention of spatial memory. Cell 112:631-43.

Li X, Li J, Gardner EL, Xi ZX (2010). Activation of mGluR7s inhibits cocaine-induced reinstatement of drug-seeking behavior by a nucleus accumbens glutamate-mGluR2/3 mechanism in rats. $J$ Neurochem 114:1368-80. 
Mahler SV, Hensley-Simon M, Tahsili-Fahadan P, LaLumiere RT, Thomas C, Fallon RV, et al. (2014). Modafinil attenuates reinstatement of cocaine seeking: role for cystine-glutamate exchange and metabotropic glutamate receptors. Addict Bio/ 19:49-60.

Maksimovic M, Vekovischeva OY, Aitta-aho T, Korpi ER (2014). Chronic treatment with moodstabilizers attenuates abnormal hyperlocomotion of GluA1-subunit deficient mice. PloS One 9:e100188.

Mead AN, Brown G, Le Merrer J, Stephens DN (2005). Effects of deletion of gria1 or gria2 genes encoding glutamatergic AMPA-receptor subunits on place preference conditioning in mice. Psychopharmacology 179:164-71.

Mead AN, Stephens DN (2003). Selective disruption of stimulus-reward learning in glutamate receptor gria1 knock-out mice. J Neurosci 23:1041-8.

Meye FJ, Valentinova K, Lecca S, Marion-Poll L, Maroteaux MJ, Musardo S, et al. (2015). Cocaine-evoked negative symptoms require AMPA receptor trafficking in the lateral habenula. Nat Neurosci 18:376-8.

Peters J, LaLumiere RT, Kalivas PW (2008). Infralimbic prefrontal cortex is responsible for inhibiting cocaine seeking in extinguished rats. J Neurosci 28:6046-53.

Petralia RS, Wenthold RJ (1992). Light and electron immunocytochemical localization of AMPAselective glutamate receptors in the rat brain. J Comp Neurol. 318:329-54.

Ping A, Xi J, Prasad BM, Wang MH, Kruzich PJ (2008). Contributions of nucleus accumbens core and shell GluR1 containing AMPA receptors in AMPA- and cocaine-primed reinstatement of cocaine-seeking behavior. Brain Res 1215:173-82.

Procaccini C, Aitta-aho T, Jaako-Movits K, Zharkovsky A, Panhelainen A, Sprengel R, et al. (2011). Excessive novelty-induced c-Fos expression and altered neurogenesis in the hippocampus of GluA1 knockout mice. Eur J Neurosci 33:161-74.

Romberg C, Raffel J, Martin L, Sprengel R, Seeburg PH, Rawlins JNP, et al. (2009). Induction and expression of GluA1 (GluR-A)-independent LTP in the hippocampus. Eur J Neurosci 29:1141-52.

Sanderson DJ, Good MA, Skelton K, Sprengel R, Seeburg PH, Rawlins JN, et al. (2009). Enhanced long-term and impaired short-term spatial memory in GluA1 AMPA receptor subunit knockout mice: evidence for a dual-process memory model. Learn Mem 16:379-86.

Schmidt HD, McFarland KN, Darnell SB, Huizenga MN, Sangrey GR, Cha JJ, et al. (2014). ADAR2-dependent GluA2 editing regulates cocaine seeking. Mol Psychiatry 20:1460-1466.

Terashima A, Young HS, Isaac JTR (2017). The AMPA Receptor Subunit GluA1 is Required for CA1 Hippocampal Long-Term Potentiation but is not Essential for Synaptic Transmission Neurochem Res doi: 10.1007/s11064-017-2425-3 
Ungless MA, Whistler JL, Malenka RC, Bonci A (2001). Single cocaine exposure in vivo induces long-term potentiation in dopamine neurons. Nature 411:583-7.

Vekovischeva OY, Aitta-aho T, Echenko O, Kankaanpää A, Seppälä T, Honkanen A, et al. (2004). Reduced aggression in AMPA-type glutamate receptor GluR-A subunit-deficient mice. Genes Brain Behav 3:253-65.

Volkow ND, Morales M (2015). The Brain on Drugs: From Reward to Addiction. Cell 162:712-25.

Vorel SR, Liu X, Hayes RJ, Spector JA, Gardner EL (2001). Relapse to cocaine-seeking after hippocampal theta burst stimulation. Science 292:1175-8.

White SL, Ortinski PI, Friedman SH, Zhang L, Neve RL, Kalb RG, et al. (2016). A Critical Role for the GluA1 Accessory Protein, SAP97, in Cocaine Seeking. Neuropsychopharmacology 41:73650 .

Wiedholz LM, Owens WA, Horton RE, Feyder M, Karlsson RM, Hefner K, et al. (2008). Mice lacking the AMPA GluR1 receptor exhibit striatal hyperdopaminergia and 'schizophrenia-related' behaviors. Mol Psychiatry 13:631-40.

Wiggins A, Smith RJ, Shen HW, Kalivas PW (2011). Integrins modulate relapse to cocaineseeking. J Neurosci 31:16177-84.

Yun IA, Fields HL (2003). Basolateral amygdala lesions impair both cue- and cocaine-induced reinstatement in animals trained on a discriminative stimulus task. Neuroscience 121:747-57.

Zamanillo D, Sprengel R, Hvalby O, Jensen V, Burnashev N, Rozov A, et al. (1999). Importance of AMPA receptors for hippocampal synaptic plasticity but not for spatial learning. Science 284:1805-11. 
Figure legends
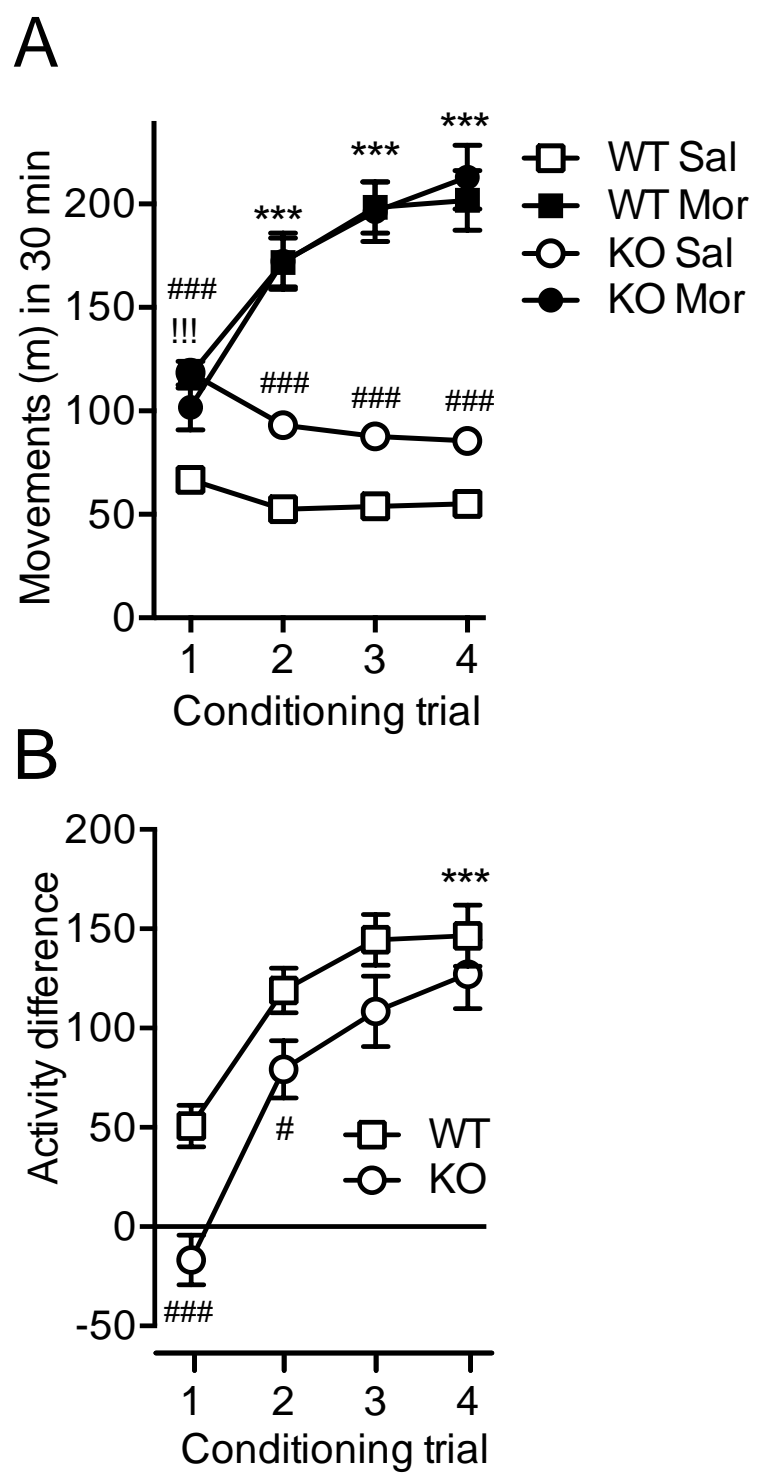

Fig. 1. Locomotor activity in conditioning trials in GluA1-WT (WT) and GluA1-KO (KO) mice. (A) Locomotor activity is depicted during each of the 30-min CS- (saline, Sal) and CS+ (morphine, Mor, $20 \mathrm{mg} \mathrm{kg}^{-1}$, s.C.) conditioning trials. Both WT and KO mice display morphine-induced sensitization. KO mice are hyperactive as shown in Sal-trials. Data are means \pm SEM $(n=22) .{ }^{* * *} p<0.001$ Sal vs. Mor within the same genotype; ${ }^{\# \#} p<$ 0.001 WT vs. KO within saline trials; !!! $p<0.001$ Sal vs. Mor in WT mice. (B) Difference in distance moved between CS- and corresponding CS+ trials [(CS+) - (CS-)]. These scores were derived from the data shown in Fig. 1A. Data are means \pm SEM $(n=22$ for each genotype). ${ }^{* * *} p<0.0011^{\text {st }}$ vs. $4^{\text {th }}$ trial for both genotypes; ${ }^{\#} p<0.05,{ }^{\# \# \#} p<0.001$ WT vs. $\mathrm{KO}$. 

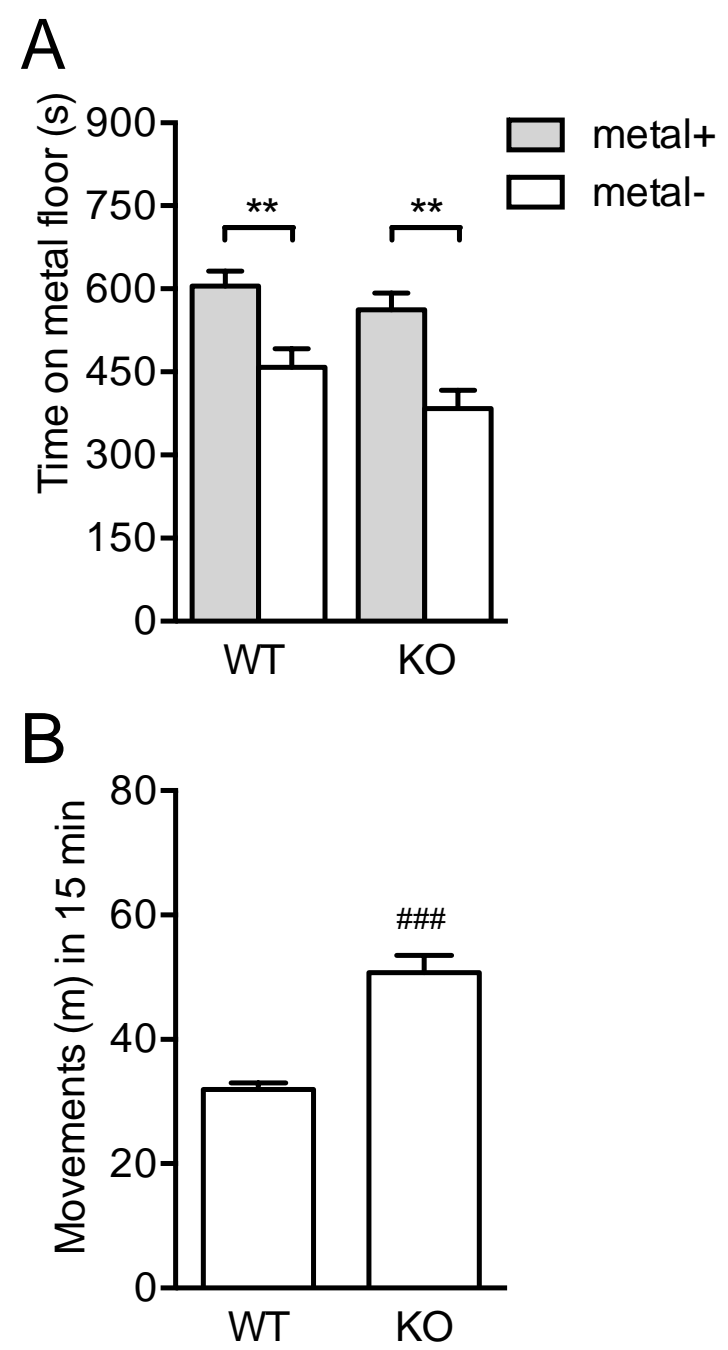

Fig. 2. The expression of morphine-conditioned place preference in GluA1-WT (WT) and GluA1-KO (KO) mice. (A) Time spent on the metal floor during the 15-min place preference test trial 24-h after the last conditioning trial. Mice were injected with saline just prior to place preference test trial. Grey bars indicate the conditioning subgroup that received morphine $\left(20 \mathrm{mg} \mathrm{kg}^{-1}\right.$, s.c.) paired with the metal floor (conditioning subgroup: metal+) during the conditioning trials. White bars indicate the conditioning subgroup that received morphine paired with the plastic floor (conditioning subgroup: metal-) during the conditioning trials. Data are means \pm SEM ( $n=11$ per genotype in conditioning subgroup). ${ }^{* *} p<0.01$ metal+ subgroup vs. metal- subgroup. (B) Locomotor activity during the 15-min place preference test trial. Data are means \pm SEM $(n=22$ for each genotype). \#\#p $p 0.001$ WT vs. KO. 


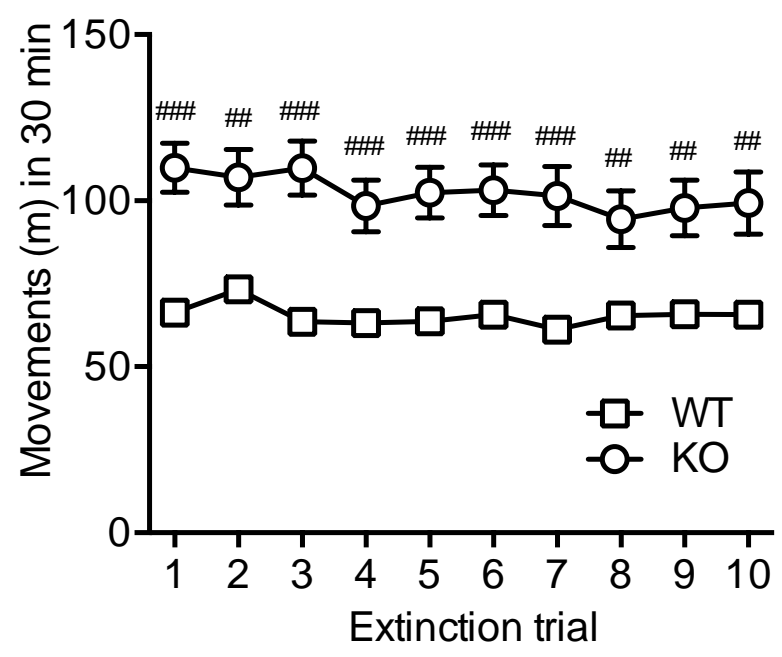

Fig. 3. Locomotor activity during the extinction trials in GluA1-WT (WT) and GluA1KO (KO) mice. Extinction was performed by pairing saline $\left(10 \mathrm{ml} \mathrm{kg}^{-1}\right.$, s.c.) with each of the floor material types (CS) during 10 consecutive days (one exposure to each CS per day). Data are means \pm SEM $\left(n=22\right.$ for each genotype). ${ }^{\prime \prime} p<0.01,{ }^{\# \#} p<0.001$ WT vs. $\mathrm{KO}$. 

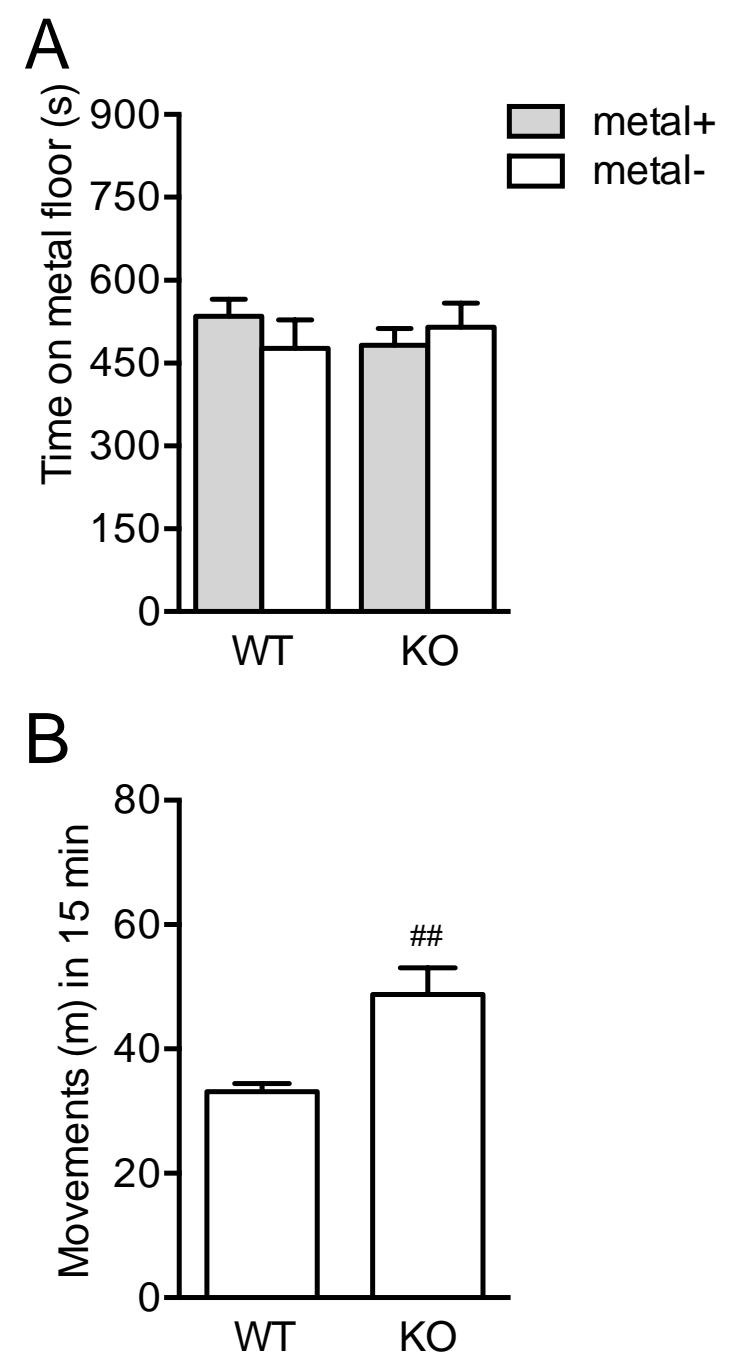

Fig. 4. Extinquished conditioned place preference in GluA1-WT (WT) and GluA1-KO (KO) mice. (A) Time spent on the metal floor during the 15-min place preference test trial 24-h after the last extinction trial. Mice were injected with saline just prior to place preference test trial. Data are means \pm SEM $(n=11)$. (B) Locomotor activity during the 15min place preference test trial. Data are means \pm SEM $\left(n=22\right.$ for each genotype). ${ }^{\# \#} p<$ $0.01 \mathrm{WT}$ vs. KO. 

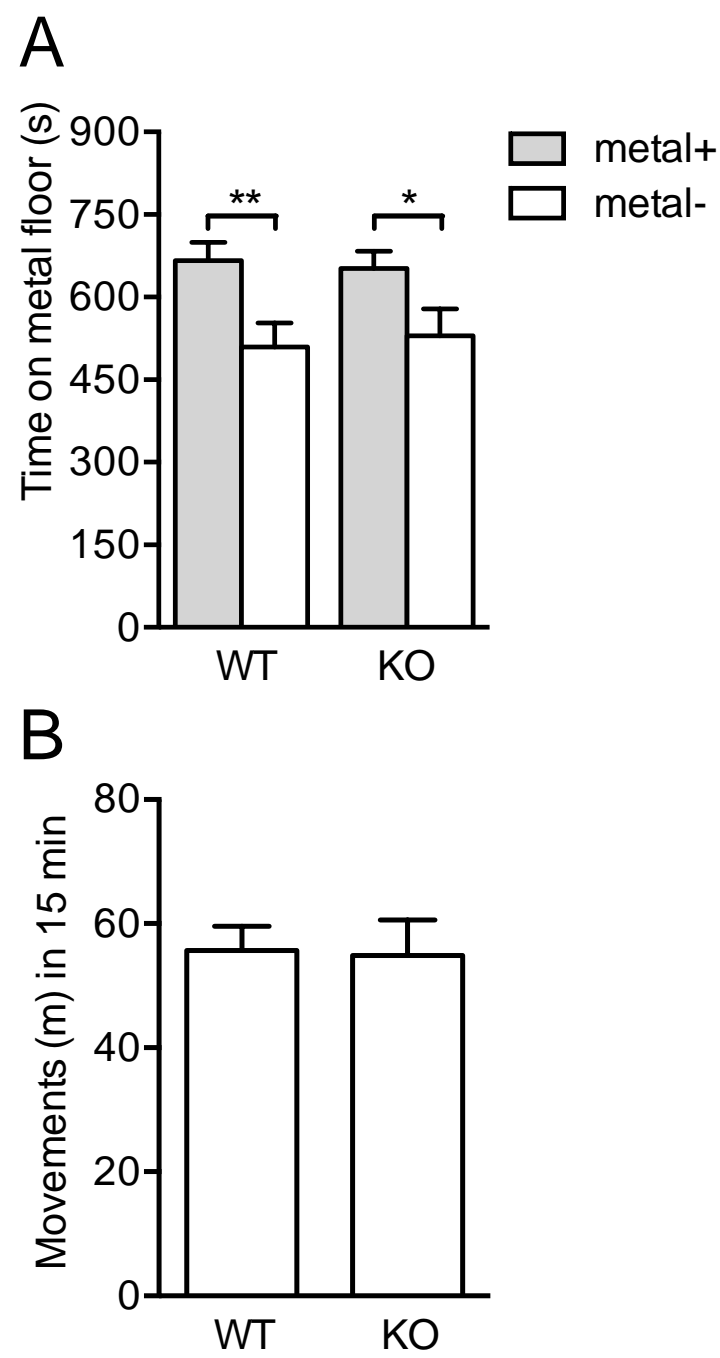

Fig. 5. Reinstatement of conditioning place preference in GluA1-WT (WT) and GluA1-KO (KO) mice. (A) Time spent on the metal floor during the 15-min place preference test trial 24-h after the extinction test. Mice were injected with morphine (10 mg $\mathrm{kg}^{-1}$, s.c. $)$ just prior to place preference test trial. Data are means \pm SEM $(n=11$ per genotype in conditioning subgroup). ${ }^{*} p<0.05,{ }^{* *} p<0.01$ metal+ subgroup vs. metalsubgroup. (B) Locomotor activity during the 15-min place preference test trial. Data are means $\pm \operatorname{SEM}(n=22$ for each genotype). 